\title{
Perfil leitor de docentes e discentes: formação de profissionais para a educação infantil e anos iniciais
}

\author{
Maria Augusta D'Arienzo" \\ Tania Mariza Kuchenbecker Rösing"*
}

\section{Resumo}

Este artigo objetiva apresentar resultados de investigação realizada com docentes e discentes de escola estadual com ensino médio curso normal sobre desenvolvimento de suas identidades leitoras. A preocupação com esse universo se justifica pelo fato de os docentes prepararem os discentes como futuros professores de crianças da educação infantil e dos anos iniciais do ensino fundamental, desencadeando o processo de formação do leitor entre os pequenos aprendizes. Os dados foram produzidos a partir de questionários, aplicados aos sujeitos referidos, sobre preferências de leitura, espaços de leitura, tempos de leitura, aspectos valorizados no ato de ler, influências recebidas nesse processo, hábitos de leitura, interesses de leitura e por manifestações culturais. Sustentaram o estudo contribuições de Chartier (1996, 2014), Zilberman (2012), Silva (2009, 2016), Santaella (2004, 2013) no estabelecimento do conceito de leitura, de formação leitora, de práticas leitoras e de novos modos de ler. Contextualizou-se o estudo no espaço da escola selecionada que mantém um projeto de leitura diária, envolvendo todos os segmentos. Constatou-se a participação efetiva dos sujeitos pesquisados no projeto citado, com efeitos em seus hábitos de leitura. Também se verificou o reconhecimento do potencial do suporte digital como promotor de leituras, embora os sujeitos participantes somente o utilizem para comunicação por meio do acesso prioritário às redes sociais. Entre as novas atitudes de leitura, observa-se, no contexto pesquisado, a preferência por textos impressos, demonstrando a influência significativa da política implementada por essa escola no desenvolvimento da leitura entre seus atores - professores, estudantes e funcionários.

Palavras-chave: Curso normal e leitura. Formação de leitores. Hábitos leitores. Leitura. Modos de ler.

\footnotetext{
Mestra em Educação pela Universidade de Passo Fundo. Professora nas redes públicas municipal e estadual de ensino em Passo Fundo/RS. E-mail: guta.doula@ gmail.com

** Doutora em Letras pela Pontifícia Universidade Católica do Rio Grande do Sul (PUCRS). Pós-doutoramento em Educação na Universidade de Extremadura, Badajoz/Espanha. Pesquisadora produtividade CNPq. Professora dos Programas de Pós-Graduação em Letras da Universidade de Passo Fundo e da Universidade Regional Integrada do Alto Uruguai e das Missões, campus de Frederico Westphalen. E-mail: tmkrosing@ gmail.com
}

Data de submissão: 31/07/2017 - Data de aceite: ago. 2017 http://dx.doi.org/10.5335/rdes.v13i2.7300 


\section{Introdução}

Quando garimpamos ou escavamos as mediações que efetiva e objetivamente contribuem para a experiência da formação de leitura na população, elevando-a ao patamar de uso real e de valor permanente de vida, veremos que essa experiência depende e resulta muito pouco do trabalho realizado pelas agências clássicas de formação, como escolas e bibliotecas, e muito mais de interações e circuitos estabelecidos em lugares relativamente distantes ou fora dessas instituições (SILVA, 2016, p. 110).

Muitos são os problemas que desafiam não apenas os dirigentes brasileiros, mas a população em geral, para reencaminhar os destinos do país, entre os quais o segmento educacional assume proporções maiores por envolver escolas, professores, estudantes de distintos níveis e sistemas. Nesse contexto de dificuldades a serem enfrentadas, a discussão sobre a formação de professores leitores, para atuar nos níveis e sistemas referidos, permanece atual. Não se podem desconsiderar os esforços despendidos por diversas instituições para superar as dificuldades emergentes da distinção entre professor de leitura e professor leitor. O que se constata é a ausência de uma política pública de leitura permanente, para desenvolver comportamentos leitores entre os profissionais responsáveis pela "escolarização da leitura literária”. Encontram-se nessa situação professores e estudantes do ensino médio curso normal (EMCN) que objetivam preparar e preparar-se como futuros professores para exercer a docência entre crianças da educação infantil e dos anos iniciais do ensino fundamental. A concretização deste estudo advém da proposta de pesquisa do universo desses dois segmentos de uma escola da rede estadual de ensino, que oferece a modalidade de curso normal, situada em cidade do interior gaúcho, que apresenta, entre seus diferenciais, um projeto de leitura diária abrangendo todos os atores da escola. Observando-se o universo das modalidades de ensino desenvolvidas no Brasil, o Curso Normal está previsto na Lei de Diretrizes e Bases da Educação Nacional, Lei no 9.394, de 20 de dezembro de 1996, e regulamentado pelo parecer da Câmara de Educação Básica, do Conselho Nacional de Educação, no 01/99, de 29 de janeiro de 1999 , e pela resolução $\mathrm{n}^{\circ} 252$, de 05 de janeiro de 2000, do Conselho Estadual de Educação do Rio Grande do Sul. Tais documentos preveem a obrigatoriedade e a gratuidade do acesso de crianças e jovens entre quatro e 17 anos de idade à escola. A complexidade do processo de desenvolvimento da leitura abrange dois grupos: futuros professores da pré-escola e dos anos iniciais do ensino fundamental e crianças da pré-escola, ainda não leitores. É um desafio aos primeiros realizarem práticas de leitura inovadoras que contemplem desde a leitura de imagens concomitantemente ao trabalho da alfabetização no contexto contemporâneo de múltiplas linguagens e tecnologias. Pretende-se apresentar, a partir dos dados levantados, a identidade 
leitora de docentes e discentes do EMCN num contexto contemporâneo em que as expectativas abrangem o desenvolvimento de novas atitudes frente ao ato de ler no contexto de educação, cultura e tecnologia. Elaboraram-se dois instrumentos de pesquisa - questionários -, sendo um para professores e outro para estudantes, com objetivo de conhecer suas identidades leitoras. $\mathrm{O}$ entendimento das questões propostas pode ser construído a partir dos conceitos a seguir descritos.

\section{Referencial teórico}

A leitura precisa ser considerada patrimônio imaterial no contexto de um patrimônio cultural. Como preceito constitucional, considera-se patrimônio cultural os bens materiais e imateriais com referência à identidade, à ação, à memória dos distintos grupos que constituem a sociedade brasileira como um todo. Em se tratando de leitura propriamente dita, é defendida como prática cultural, pois abrange experiências de leitura individuais (diferentes olhares de mundo) e sociais (interações com outros leitores) em diferentes espaços e tempos, acumulando conhecimentos registrados na memória do leitor, que a repercutem no coletivo (CHARTIER, 1996, 2014). Os modos de ler, ou seja, de compreender textos de naturezas variadas, apresentados em suportes diferenciados, estão sendo modificados com o uso de novas tecnologias, o que pressupõe o desenvolvimento de práticas de leitura inovadoras na escola e fora dela.
A leitura literária implica o desenvolvimento da sensibilidade do leitor, uma vez que se constitui em experiência estética singular, irrepetível, única. Realiza-se pelo envolvimento do leitor com textos literários apresentados em diferentes suportes, entendendo a palavra em sua polissemia, em sua plurissignificação. Entende-se por

educação literária desde a perspectiva da formação do leitor literário, do leitor autônomo que decide buscar na leitura do texto artístico uma forma de evasão, e ao mesmo tempo de reencontrar-se com o mundo que o rodeia e de reconhecer-se a si mesmo. Concebe-se, portanto como um ato de liberdade individual - uma liberdade em certo modo relativa, pois depende entre outras coisas da possibilidade de acesso a determinadas obras (QUILES, 2013, p. 384-385, tradução nossa).

Nessa dimensão, a leitura é uma prática construída na sociedade e na escola e culturalmente transmitida pelos agentes sociais e culturais. No ensino médio, a preocupação com o ensino da literatura não tem sido essencial, uma vez que permite aos alunos um trânsito para o vestibular, e o ensino superior, sem foco no conjunto de áreas do conhecimento responsáveis por uma formação humanística.

O ensino da literatura não precisava de qualquer justificativa enquanto a escola secundária conservou a natureza humanística trazida das suas origens (ZILBERMAN, 2012, p. 202).

Essa realidade no EMCN precisa ser diferente, observando-se o objetivo de formar futuros professores leitores, capazes de divulgar textos literários 
entre crianças de forma a identificar a natureza desses textos, sua originalidade, sua construção singular e seus efeitos na formação literária numa perspectiva profissionalizante. Corrobora esse posicionamento a declaração de Zilberman:

Convertida em profissionalizante ou transformando em uma aspiração para grupos sociais que, por várias razões, dificilmente chegarão à universidade, o ensino médio teve de redefinir suas expectativas em relação à presença da literatura no currículo. De um lado, porque o conhecimento da literatura não é propriamente profissionalizante [...]. De outro os estudos literários não são fundamentais para o percurso acadêmico do universitário, a não ser que se dirija para o curso de letras (2012, p. 202).

Para desenvolver a leitura literária, várias ações precisam ser desencadeadas, lembrando que a divulgação de textos pode ser pela narrativa oral, com aproveitamento pleno de acervos impressos em diferentes materialidades, representativos de uma variedade de gêneros. Seus conteúdos poderão ser apropriados pelo leitor em meio a manifestações artísticas e culturais podendo, inclusive, ser apresentados em diferentes suportes com outras linguagens. No que diz respeito à realização de práticas leitoras hipermidiais, pode-se organizá-las e entendê-las pelo

[...] contato com uma variedade de textos e de linguagens do impresso ao digital. Textos literários harmonizados com música, ilustrações, pinturas, quadrinhos, charges, cartuns, sites, aplicativos para tablets relacionados ao tema são apresentados. É um processo de vivência cultural ampla, que pode ser mais ou menos profunda dependendo do conhecimento prévio de cada leitor em formação presente (RÖSING, 2015, p. 13).
Essas práticas propiciam ao leitor vivências em diferentes linguagens e suportes, enquanto experiências estéticas que enriquecem o seu conhecimento prévio, o qual influenciará a significação dos textos com os quais poderá se envolver.

A organização e a implementação de práticas leitoras hipermidiais pressupõem a ação de professores leitores, capazes de entender a natureza literária dos textos, apreciá-la, divulgando-os a partir desses recursos literários, apresentados também em contexto tecnológico.

O professor leitor é aquele que se envolve com textos literários, sejam eles clássicos, sejam contemporâneos, mesmo sem aval da crítica tradicional, cujos conteúdos e recursos estilísticos são não apenas apreciados individualmente, mas também socializados com o outro, com os outros. Não é suficiente ler literatura. Não é suficiente falar sobre literatura. Faz-se necessário compartilhar a experiência de leitura enquanto experiência estética no diálogo com os outros.

$\mathrm{Na}$ perspectiva defendida por Silva, o professor precisa formar-se, também, enquanto profissional leitor:

O magistério, em termos de trabalho e de atualização, está calcado em experiências de leitura. Por dever de ofício e expectativa social, o professor tem na leitura, além de instrumento e prática, uma forma de atuar ou agir, seja porque ele (o professor) simboliza leituras já realizadas e assimiladas, seja porque faz a mediação e informa leituras relacionadas à matéria que ensina, seja porque o conhecimento, para ser organizado e dinamizado, exige competências multifacetadas de leitura (2009, p. 26). 
O propósito de formar professores leitores emerge de um contexto pleno de perplexidades, no qual as pessoas se comunicam a distância, envolvidas por telas e redes sociais, misturando-se na multidão, imersas em incontáveis informações fragmentadas, com reflexos na construção do conhecimento e no diálogo entre as pessoas. Silva amplia a complexidade desse contexto ao declarar:

Uma atualidade regida pelo culto do espetáculo, simplificando e banalizando as soluções aos problemas sociais, quando não promovendo ininterruptamente a demonização de tudo e de todos. Uma atualidade onde o debate, como uma parte essencial do diálogo, simplesmente evaporou. Uma atualidade conduzida pela razão instrumental onde impera o utilitarismo, a descartabilidade, o presentismo sem passado nem futuro, o sucesso sem esforço ou trabalho. Uma atualidade brasileira que retorna à barbárie, como forma de protestar, pondo compulsivamente nas ruas a desavença e a violência como forma de expressar o desacordo (2016, p. 119).

Para atuar nesse contexto, o professor leitor precisa entender a complexidade do ato de ler e formar-se como leitor múltiplo e formar leitores com perfil cognitivo que atenda às peculiaridades dessa multiplicidade. O primeiro envolvimento do leitor literário em formação tem sido com o livro, que determina uma relação individual, silenciosa, solitária, profunda entre o leitor e a obra. Mesmo num momento histórico marcado pelo tumulto, pela velocidade, há lugar para a meditação e a reflexão. Este primeiro tipo de leitor Santaella (2004) intitula como leitor contemplativo, meditativo.
A leitura do livro é, por fim, essencialmente contemplação e ruminação, leitura que pode voltar às páginas, repetidas vezes, que pode ser suspensa imaginativamente para a meditação de um leitor solitário e concentrado (SANTAELLA, 2004, p. 24).

Acrescenta-se a esse primeiro tipo de leitor a oportunidade, criada a partir da Revolução Industrial, de as pessoas circularem nos espaços criados pela ampliação da sociedade capitalista. Inserem-se em locomotivas e estações ferroviárias, máquinas a vapor e trabalhadores de fábricas, trazendo novos matizes às cidades, o que atraiu sobremaneira a atenção das pessoas em geral. Luzes, movimentos, variedades de cenários e de signos provocaram novos olhares e permitiram a emergência de um leitor que se movimenta pelas cidades, desenvolvendo uma crítica sobre a composição mercadológica em que se transformaram os diferentes ambientes, alimentando o consumismo. Então, o leitor movente

[...] é o leitor treinado nas distrações fugazes e sensações evanescentes cuja percepção se tornou uma atividade instável, de intensidades desiguais. É enfim o leitor apressado de linguagens efêmeras, híbridas, misturadas (SANTAELLA, 2004, p. 29).

A chegada à era digital propiciou a substituição do leitor do livro, enquanto objeto manipulável, pelo leitor da tela que veicula o texto eletrônico para ser lido pelo leitor imersivo. É assim chamado porque,

[...] no espaço informacional, perambula e se detém em telas e programas de leitura num universo de signos evanescentes e eternamente disponíveis (SANTAELLA, 2013, p. 271). 
É um novo tipo de leitor cujas habilidades são distintas do leitor do livro impresso, bem como das empregadas pelo espectador de cinema, televisão,

[...] esse leitor conecta-se entre nós e nexos, seguindo roteiros multilineares, multisequenciais e labirínticos que ele próprio ajuda a construir ao interagir com os nós que transitam entre textos, imagens, documentação, músicas, vídeos, etc. (SANTAELLA, 2013, p. 271).

Esses três tipos de leitor - contemplativo, movente, imersivo - se constituem numa complexidade que precisa ser observada, uma vez que devem coexistir, valorizando cada um em sua individualidade, relevados pela importância da complementariedade que integram.

A evolução das tecnologias digitais que propiciam o surgimento de equipamentos móveis, aprimorando a comunicação e o acesso à internet e às redes sociais, provoca mudanças radicais no ser e no agir das pessoas. As relações com espaço e tempo se modificam, permitindo às pessoas encarar problemas sob diferentes pontos de vista, ter acesso e assimilar informações, responder ao fluxo acelerado de imagens e textos num ambiente em constante mutação, transformando-se as pessoas em agentes capazes de realizarem múltiplas tarefas concomitantes numa dimensão de superficialidade. Nesse contexto, surge o leitor ubíquo que:
[...] não é outra coisa a não ser uma expansão inclusiva dos perfis cognitivos dos leitores que o precederam e que ele tem por tarefa manter vivos e ativos. Ademais, é um leitor que de apreender com o sentido também emerge em contextos coletivos e colaborativos, como a criatividade opera numa cultura aberta, baseada em amostragem, apropriação, transformação e em traduções contínuas (SANTAELLA, 2013, p. 282).

O desenvolvimento concomitante dos quatro tipos de leitores sugeridos por Santaella passa a se constituir num desafio aos profissionais da educação que vivem, contemporaneamente, um contexto complexo e rico de oportunidades de leitura. Precisam convencer-se de que o momento impõe ações de diferentes leitores num mesmo leitor no entendimento e na transformação do mundo.

Para que esse desenvolvimento possa acontecer, o segmento educacional deve promover uma reflexão profunda sobre os desafios que a leitura nessa dimensão propõe, ao mesmo tempo deve estimular os atores da escola e da universidade a contribuírem com as mudanças subjacentes ao ato de ler e aos seus efeitos. Esse esforço pode resultar na construção e na implementação de uma política de leitura com capacidade para não apenas ampliar os índices de leitura no país, mas também provocar a transformação de hábitos em comportamentos leitores permanentes.

Para tanto, faz-se necessária a manutenção de programas governamentais de distribuição de livros didáticos e literários, bem como de infraestrutura tecnológica, facilitando o acesso de estudantes e 
professores a acervos e suportes variados e qualificados. É o caso de docentes do ensino médio curso normal que objetivam formar professores capacitados a elevar o nível de aprendizagem de alunos da educação infantil e dos anos iniciais do ensino fundamental.

\section{Metodologia}

Para o desenvolvimento do estudo, participaram 18 professores e 25 alunos do Ensino Médio Curso Normal de David Canabarro/RS. Entre os primeiros, predomina o gênero feminino (14) com idades entre 45 e 62 anos; entre os alunos, 24 são do gênero feminino com idades entre 14 e 19 anos. Em se tratando de curso de formação de professores, profissionalizante, portanto, predominam mulheres o que permite considerar o magistério como uma profissão preponderantemente feminina.

Todos os professores são graduados em cursos de licenciatura, e, do total, 15 realizaram curso de especialização; por serem oriundos da escola pública, são ambientados com esse sistema de ensino.

Produziram-se os dados em dois questionários (um para professores e um para alunos) cujos formulários foram preenchidos pelos próprios sujeitos, tanto professores quanto alunos, e as respostas foram elaboradas no contexto da escola, sendo observado o ritmo de cada sujeito. $O$ instrumento foi constituído de nove seções, a seguir nominadas: perfil da amostra, identificação de textos (jornais, revistas, livros), suportes de leitura, espaços de leitura, tempos de leitura, aspectos valorizados na leitura, preferências de leitura, hábitos de leitura - período anterior à leitura, durante a leitura, período posterior à leitura -, interesses.

\section{Discussão de dados}

Indagados sobre a leitura de jornais, onze professores revelam ler numa periodicidade diária e seis, semanalmente; e, entre os alunos, confrontando-se com essa realidade, somente um respondeu diariamente e um semanalmente. Constata-se que o suporte jornal é de preferência dos professores, mas não dos alunos, uma vez que os dados iniciais se referem a jornal impresso. Entre os docentes, o jornal exerce uma posição de destaque, contrariando os resultados da pesquisa Retratos da Leitura do Brasil (RLB), edição de 2015 (FAILLA, 2016), em que esse suporte não se encontra entre os preferidos dos entrevistados. $\mathrm{O}$ acesso dos estudantes às informações ocorre pela interação com outros meios ou, o que é preocupante, não se constitui numa curiosidade da faixa etária em seu cotidiano.

A leitura de revistas pelos professores se equivale à de jornais em preferência (quinze responderam ler semanalmente e dois diariamente), destacando-se o fato de lerem em casa, o que permite inferir-se que são assinantes de periódicos. Os alunos confirmam não preferirem revis- 
tas (três responderam diariamente e seis semanalmente), ratificando comportamento similar em relação a jornais. Os dados auferidos na pesquisa RLB (2015) destacam uma diminuição do hábito de ler revistas, independentemente da idade dos entrevistados. O que surpreende nesses últimos dados é o distanciamento dos leitores em formação de textos curtos de temas atuais, abrangendo textos verbais e imagens, peculiares às revistas, cuja leitura poderia contribuir com o desenvolvimento do gosto por essa atividade cognitiva.

Nas respostas sobre leitura de livros e sobre o fato de se considerarem leitores assíduos, os professores dividiram-se entre respostas afirmativas (12), relativizando-as com a declaração de que leem poucos livros (6). Entre os alunos, 21 consideram-se leitores assíduos de livros, confirmando o esforço de sua escola na realização de um projeto diário de leitura, ${ }^{1}$ que envolve professores, alunos e funcionários. Sobre o número de livros lidos no último ano, a média, entre os professores, é de 6 livros e, entre os alunos, de 7,9. Esse resultado é mais satisfatório do que os índices apresentados para o mesmo item na pesquisa RLB: 4,96 livros lidos no último ano (FAILLA, 2016, p. 252).

Quanto ao gênero dos livros preferidos ou à temática predominante no livros, tanto professores quanto alunos, em sua maioria, responderam ser romance. Essa preferência se equipara à pesquisa RLB (2015), que apresenta o romance entre as primeiras preferências, ao lado da Bíblia e de livros religiosos, os gêneros lidos frequentemente.

No que diz respeito à preferência de suporte, nove professores responderam ser o impresso e nove, ser indiferente. Entre os alunos, oito responderam ser impresso, dois digital e catorze indiferente. Essas respostas se dividem, demonstrando o reconhecimento dos novos suportes, mas a dificuldade de acessá-los permanentemente e para assuntos de formação pessoal e profissional. Essa preferência pode ser abrangida na pesquisa RLB (2015), na questão que indaga se os sujeitos já leram e-books e livros digitais: a resposta predominante indica que $74 \%$ dos sujeitos nunca leu. Há uma resistência dos professores em assumir novas tecnologias, o que é lamentável, considerando a pluralidade de recursos nelas existentes. Outro ponto a ser observado é o fato de os jovens usarem o suporte como entretenimento, desconsiderando o seu potencial para a construção de novos conhecimentos. Redes sociais, em especial o Facebook, constituem a forma de comunicação preferida de professores e alunos. Esse dado se confirma na pesquisa RLB (2015), quando se identifica o uso da internet com a finalidade de trocar mensagens no WhatsApp ou no Snapchat, num total de $66 \%$ dos entrevistados. Mais especificamente no que diz respeito ao acesso a redes sociais ou blogs que falem sobre livros ou literatura, apenas $8 \%$ manifestou-se positivamente. Nessa dimensão, 
constata-se uma preferência por texto literário impresso.

Outra perspectiva importante na leitura é a sua realização no espaço da biblioteca. Constata-se, independentemente da dinâmica de aquisição de livros e de divulgação desses, que professores e alunos não têm o hábito de usar este espaço para ler. Nos dados da pesquisa RLB (2015), a grande maioria prefere ler, em ordem de predominância, em casa, na sala de aula e raramente em bibliotecas, o que determina uma reflexão sobre a necessidade de ressignificar esse espaço escolar.

Sobre os aspectos valorizados na leitura, professores e alunos consideram que a mesma ativa/mobiliza/desenvolve capacidades cognitivas, amplia a cultura, proporciona prazer, desenvolve a sensibilidade, facilita a integração entre pares e propicia sucesso profissional. Coincidem com essas respostas os dados da pesquisa RLB (2015) que identificam, em sua grande maioria, a leitura como veículo do conhecimento para, em ordem de importância, atualização e crescimento profissional, como forma de propiciar melhores experiências vivenciais e, assim, contribuir com uma trajetória exitosa de vida.

$\mathrm{Na}$ indicação de preferência de leitura entre os jovens, encontram-se títulos como A culpa é das estrelas, de John Green, A última música, de Nicholas Sparks, Quem é você, Alasca?, de John Green, e outros autores, como Ana Miranda, Thalita Rebouças, Emilly Giffin, Caio Riter, Paulo Coelho e Edir Macedo.
Salienta-se que, entre autores literários, aparecem nomes como o de Mário Quintana, Ana Maria Machado ao lado de Ana Miranda. Já entre professores, predominam os de autoajuda, não podendo ser omitidos os nomes de Eduardo Galeano e Jostein Gaarder, não sendo lembrados nomes de escritores contemporâneos brasileiros convidados para eventos que eles consideram referência. ${ }^{2}$ No contexto da pesquisa RLB (2015), as respostas apontam, como livro mais lido, a Bíblia e, na sequência, best-sellers, como A culpa é das estrelas, ficando os livros literários em posição inferior.

Perguntados sobre quem influenciou no desenvolvimento do interesse pela leitura, responderam os alunos terem sido professores no contexto da escola, seguidos por colegas, funcionários e responsáveis pela biblioteca. Já os professores referem seus próprios colegas ao lado de responsáveis pela biblioteca. As respostas referendam o projeto de leitura desenvolvido no contexto da escola com a participação de todos os atores. Na família, os alunos referiram, com a mesma importância, pai e mãe e, entre outras influências, os amigos, a televisão, a internet e veículos de divulgação de diferentes naturezas. Os professores dividem entre pai, mãe e irmãos o papel de estimulador do ato de ler. Entre outras influências, enfatizam a participação de amigos nesse processo de descoberta do interesse pela leitura. Nos resultados da pesquisa RLB (2015), quem mais influenciou os leitores a lerem foi, em 
primeiro lugar, a mãe ou um responsável do sexo feminino e, em segundo lugar, algum professor ou professora.

Ao serem perguntados sobre seus hábitos de leitura, professores e alunos declararam, em sua maioria, que estabelecem objetivos para sua leitura, analisam os dados da capa, buscam informação sobre o autor antes de lerem o livro. Durante a leitura, relacionam o conteúdo que estão lendo com suas experiências de vida, sem deixar de levantar hipóteses sobre o que estão lendo, fazem perguntas a si mesmos sobre esse conteúdo. Após a leitura, declaram os alunos não reler o texto e também se manifestaram pouco preocupados em rever as hipóteses iniciais. Entre os professores, o posicionamento é contrário.

$\mathrm{Na}$ ampliação do conceito de leitura, foram interrogados sobre a possibilidade de ter acesso presencial a apresentações e/ou exposições, tendo emergido resposta positiva entre professores e alunos por meio da preferência por teatro, dança, música e pintura/escultura.

Os professores foram solicitados a responder sobre interesses de leitura de textos contemporâneos, clássicos e teóricos, sem mencionar se são literários ou não. Predominou ampla preferência por textos contemporâneos, seguidos por textos clássicos e, por último, textos teóricos.

A aproximação com o universo da escola, identificando as motivações de leitura de docentes e discentes, constitui-se num desafio à valorização de princípios teóricos subjacentes a essas ações e à introdução de novos conceitos capazes de contribuir para o surgimento e a consolidação de novos modos de ler. Assume significado maior, paralelamente a essas ações, a criação de estratégias de leitura para serem implementadas entre crianças da educação infantil e dos anos iniciais do ensino fundamental, objetivando a formação de leitores criativos, críticos e autônomos.

Com base nos dados levantados na escola entre professores e alunos, cotejados com resultados da RLB (2015), pode-se inferir a importância da atuação de mediadores de leitura a partir de uma política de leitura no contexto da escola, cujas leituras indicadas têm preenchido preferências, interesses e necessidades dos leitores em formação. Ficam em segundo plano as necessidades de comunicação com o uso de equipamentos móveis, considerando-se a precariedade do potencial da rede no município pesquisado.

\section{Considerações finais}

O momento histórico no qual se vive a proliferação dos equipamentos móveis, promovendo a leitura ubíqua, permite o levantamento de hipóteses, entre as quais se encontra a preferência de leitura no uso de smartphones e tablets, especialmente entre os jovens. Ao se deparar com a realidade de uma escola no interior da região sul brasileira, em que os professores constroem uma política de leitura a ser conquistada diariamente 
com a prática coletiva do ato de ler, a lógica da contemporaneidade modifica-se, invertendo as hipóteses construídas previamente.

A investigação revelou a preferência pela leitura do livro impresso, comprovando efeitos do projeto de promoção da leitura desenvolvido no espaço da escola selecionada, de natureza profissionalizante. Os atores, docentes e discentes, demonstram estar satisfeitos com esse tipo de leitura que, se de um lado se preocupa com a possibilidade da realização de uma leitura silenciosa, solitária, reflexiva, de outro, se constitui como leitura fragmentada, superficial. Não se evidencia a diferença entre ler o todo de um livro, que, mesmo sendo lido em partes, oferece ao leitor em formação o significado de sua totalidade, diferentemente da leitura de fragmentos, plena de superficialidade por não remeter a um todo significativo.

Essa modalidade de leitura diária na escola pode ser entendida paradoxalmente. De um lado propicia o estabelecimento de uma rotina que beneficia a necessidade permanente de ler para informar-se, para envolver-se mais estreitamente com textos de natureza artística que ampliem a imaginação, a sensibilidade. De outro, facilita o exercício de uma leitura superficial, desenvolvida por pessoas de diferentes faixas etárias, pela aproximação pouco intensa, como a prática realizada com textos produzidos e consumidos nas redes sociais de comunicação.
Estão distanciados os sujeitos investigados - professores e alunos - de leituras canônicas defendidas em meio universitário e pela crítica tradicional, mas próximos de materiais disponibilizados pela escola no espaço da biblioteca, cuja seleção tem observado seus interesses, preferências e necessidades. O gosto pela leitura poderá ser reproduzido pelos futuros professores, alunos de ensino médio curso normal, entre as crianças com as quais irão exercer a docência, independentemente de ser referendado por preceitos canônicos.

Nesse contexto pesquisado, podem-se sugerir estratégias de aperfeiçoamento do projeto diário de leitura, considerando a disposição de professores e alunos para a reflexão sobre suas práticas, a diversificação e o aprofundamento desses procedimentos.

Os sujeitos pesquisados incluem, em suas práticas individuais e sociais contemporâneas, o uso de equipamentos móveis. Faz-se necessário apresentar-lhes novas perspectivas para seu aproveitamento no meio educacional e cultural, ampliando-lhes as possibilidades de aprimoramento pessoal e profissional no uso e na produção de aplicativos, por exemplo, além da familiaridade com games que qualifiquem as estratégias de aprendizagem na sala de aula e fora dela.

Considera-se positivo o engajamento da comunidade escolar na prática de leitura de materiais impressos, sem se desconhecer o crescente interesse das 
pessoas em geral pela manipulação de equipamentos móveis, constituindo um novo modo de ler, de escrever, de se comunicar, sem a preocupação de sobrepô-los ao potencial da televisão entre os suportes mais populares.

Pretende-se promover, desse modo, efeitos significativos na ação de docentes e discentes do ensino médio curso normal, pelo compromisso que assumem ao desencadearem processos de formação de leitores entre crianças da educação infantil e dos anos iniciais do ensino fundamental. A inserção num projeto contínuo e permanente de leitura, independentemente dos suportes com os quais se envolvam os leitores em formação, constitui-se na esperança de que se começa a entender a leitura como sustentação de práticas individuais e sociais mais aprimoradas.

\section{Reading profile of teachers and students: education of professionals for childrens education and first years}

\section{Abstract}

This article aims at presenting results of investigation performed with teachers and students from a public state high school with teaching technical majoring about the development of their readers identity. The preocupation with this univers is justified by the fact that the teachers prepare the students as future teachers of children from kindergarten to elemetary school, initiating the process of readers formation among the students. Data was produced from questionnaires about reading preferences, reading spaces, reading times, aspects valued in the act of reading, influences received in this process, reading habits, reading interests and interests for cultural manifestations. This study was supported in contribution from Chartier (1996, 2014), Zilberman (2012), Silva (2009, 2016), Santaella $(2004,2013)$ in the establishment of the concept of reading, reading formation and reading practices as well as neww forms of reading. In addition, the recognition of the potential of the digital support as reading promoter, in spite of the fact that the participants mainly access this type of communication in social media. Among the new reading attitutes, it was observed, in the research context, the preference for printed texts, demonstrating the influence of the policy implemented by the school in the development of reading amon actors - teachers, students and staff.

Keywords: Reader formation. Reading. Reading forms. Reading habits. Teaching majoring technical course and reading.

\section{Notas}

1 Este projeto mantido pela escola prevê, no início de cada turno, a utilização de 20 minutos para leitura de textos selecionados pelos próprios leitores em formação sem preocupação com a qualidade dos materiais, a sequência da leitura e a complexidade textual crescente na seleção.

2 Os professores consideram referência a programação das diferentes edições das Jornadas Literárias de Passo Fundo, realizadas durante 34 anos, e das Jornadinhas Nacionais de Literatura, realizadas por 7 edições bienais, com programação para crianças e jovens entre 6 e 18 anos de idade. Referem também à programação da Jornight, evento literário destinado a jovens 
entre 15 e 25 anos de idade, alunos de cursos técnicos, de educação de jovens e adultos e de primeiro nível de graduação, preferencialmente do ensino noturno.

\section{Referências}

BRASIL. Constituição da República Federativa do Brasil. Brasília, DF: Senado, 1988.

Lei $\mathrm{n}^{\mathrm{0}} 9.394$, de 20 de dezembro de 1996. Lei de Diretrizes e Bases da Educação Nacional. Brasília, DF: Ministério da Educação, 1996.

. Parecer $n^{\circ} 01 / 99$, de 29 de janeiro de 1999. Brasília, DF: Câmara de Educação Básica, do Conselho Nacional de Educação, 1999.

CHARTIER, Roger (Org.). Práticas da leitura. São Paulo: Estação Liberdade, 1996.

A leitura como prática cultural. $R e$ vista Observatório Itaú Cultural, São Paulo, v. 17, p. 19-39, ago./dez. 2014.

FAILLA, Zoara (Org.). Retratos da leitura no Brasil 4. Rio de Janeiro: Sextante, 2016.

QUILES, Maria del Carmen. Lectura literaria. In: NÚÑES, Eloy Martos; FERNÁNDEZ-FÍGARES, Mar Campos (Coord.). Diccionario de nuevas formas de lectura $y$ escritura. Badajoz, Espanha: Red Internacional de Universidades Lectoras; Santillana, 2013. p. 384-386.

RIO GRANDE DO SUL. Resolução $n^{\circ}$ 252, de 05 de janeiro de 2000. Porto Alegre, RS: Conselho Estadual de Educação do Rio Grande do Sul, 2000.

RÖSING, Tania Mariza Kuchenbecker. A constituição do sujeito leitor: etapas a serem percorridas. In: RÖSING, Tania Mariza Kuchenbecker et al. Roteiro de práticas leitoras para a escola III. Histórias de enganação e assombração: brincando com a morte. Passo Fundo: UPF Editora, 2015.
SANTAELLA, Lucia. Comunicação ubíqua: repercussões na cultura e na educação. São Paulo: Paulus, 2013.

Navegar no ciberespaço: o perfil cognitivo do leitor imersivo. São Paulo: Paulus, 2004.

SILVA, Ezequiel Theodoro. O professor leitor. In: SANTOS, Fabiano dos; MARQUES NETO, José Castilho; RÖSING, Tania M. K. Mediação de leitura: discussões e alternativas para a formação de leitores. São Paulo: Global, 2009.

Biblioteca, inovação e comunidade. In: RÖSING, Tania Mariza Kuchenbecker; FERRARI, Adriana Cybele (Org.). Biblioteca, inovação e comunidades leitoras. Passo Fundo: UPF Editora, 2016.

ZILBERMAN, Regina. A leitura e o ensino da literatura. Curitiba: InterSaberes, 2012. 